\title{
Resolving the conflict of nuclear wastewater discharging into the ocean based on the GMCR
}

\author{
Benshuo Yang and Haojun Xu \\ Ocean University of China-Laoshan Campus, Qingdao, China
}

\begin{abstract}
Purpose - Japan's decision to release nuclear wastewater into the Pacific Ocean in 2023 has sparked strong opposition at home and abroad. In this study, Graph Model for Conflict Resolution (GMCR) method is adopted to analyze the conflict problem, and reasonable equilibrium solutions are given to solve the conflict event.

Design/methodology/approach - In this study, GMCR is adopted to solve the conflict problem. First, identify the key decision-makers (DMs) on the issue of nuclear effluent and the relevant options they might adopt. Second, the options of each DM are arranged and combined to form a set of feasible states. Thirdly, the graph model is constructed according to the change of DM's options, and the relative preference of each DM is determined. Finally, the conflict problem is solved according to the definition of GMCR equilibrium.

Findings - Discharging nuclear wastewater into the ocean is not the right choice to solve the problem. Developing more space to store nuclear wastewater is more conducive to the protection of the ocean environment.

Practical implications - It is undesirable for the Japanese government to unilaterally discharge nuclear wastewater into the ocean. Objectively assessing the radioactivity of nuclear wastewater and the cooperation of relevant stakeholders can better solve this conflict.

Originality/value - The problem arising from Japan's releasing plan is complicated because of a lack of information and the existence of multiple stakeholders, while GMCR can help us with a better view of the current circumstance in the conflict.
\end{abstract}

Keywords Ocean management, Ocean environment, Nuclear wastewater, GMCR

Paper type Research paper

\section{Introduction}

On 13 April 2021, Japan announced it would release 1.25 million tons of treated nuclear wastewater into the Pacific Ocean in two years. The decision has been strongly questioned and opposed by residents and neighboring costal countries including China, Russia, South Korea and North Korea (Nogrady, 2021).

The radioactive wastewater results from a disastrous nuclear meltdown accident in Fukushima Daiichi Nuclear Power Plant (FDNPP), which is in the charge of Tokyo Electric Power Company (TEPCO). On 11 March 2011, the Great Sendai Earthquake and a following

(C) Benshuo Yang and Haojun Xu. Published in Marine Economics and Management. Published by Emerald Publishing Limited. This article is published under the Creative Commons Attribution (CC BY 4.0) licence. Anyone may reproduce, distribute, translate and create derivative works of this article (for both commercial and non-commercial purposes), subject to full attribution to the original publication and authors. The full terms of this licence may be seen at http://creativecommons.org/licences/by/4.0/ legalcode

This research is supported by the National Social Science Fund Major Projects (14ZDB151); National Science Foundation of China under Grants (41701593, 71371098, 71571157); National Key Research and Development Program of China (2016YFC1402000); Public welfare industry research projects (201305034, 201405029); The Ministry of Education Philosophy and Social Sciences Development Report Cultivation Project (13JBGP005); General Financial Grant from the China Postdoctoral Science Foundation (2015M580611); Qingdao Postdoctoral Application Research Project (251); Fundamental Research Funds for the Central Universities (201613006, 201564031).

Conflict of nuclear wastewater discharging

Received 18 August 2021 Revised 17 September 2021 Accepted 13 October 2021 
MAEM

5,1

giant tsunami hit FDNPP, leading to hydrogen explosions and severe radioactive contamination release. In the time since the accident, the water for cooling nuclear reactors, as well as the rainwater and groundwater seeping into the reactors, has generated large amounts of nuclear wastewater, which is transported to large tanks in the plant area for storage (TEPCO, 2021a). However, it is expected that all tanks would be filled up around the middle of 2022, and limited waste water storage space have led Japan to decide to discharge contaminated nuclear wastewater into the sea (TEPCO, 2021b).

According to TEPCO, wastewater is treated in a multi-nuclide removal facility (Advanced Liquid Processing System), thereby removing most of the 62 isotopes except for tritium, which means in addition to tritium, there are still other radionuclides remaining in the treated wastewater, such as ${ }^{14} \mathrm{C},{ }^{137} \mathrm{Cs},{ }^{134} \mathrm{Cs}$ (TEPCO, 2021c). To reduce the risk of discharged contaminated water, Japan proposed to gradually release the treated water after repurification and diluting the tritium concentration to $1 / 70$ of the radiation safety standard for drinking water of the World Health Organization. Although Japan's decision seems to be in line with the international practice of nuclear wastewater discharge, it is distinctive from the normal operation of nuclear power plants to release such large amounts of radioactive wastewater to the ocean, especially after a serious nuclear leakage in 2011 (Buesseler, 2020).

The released radionuclides would spread rapidly along with ocean currents, causing widespread impact. It is reported that the artificial radioactive isotopes from FDNPP have arrived western margin of the Pacific Ocean and west coast of North America within 2 years after the Fukushima Nuclear Accident (Smith et al., 2015; Suseno and Wahono, 2018).

Though sea currents would help dilute nuclear pollutants in the water near Japan, isotopes contained in tanks with high seafloor sediment-water distribution coefficient and high biological concentration factor including ${ }^{14} \mathrm{C},{ }^{137} \mathrm{Cs}$ and ${ }^{134} \mathrm{Cs}$ do not disperse with ocean currents, but easily accumulate on seabed and in marine organisms around Japan, posing a lasting threat to the local marine ecosystem (Lu et al., 2021). Marine lives and human are tightly connected by the food web, resulting in a further accumulation in organisms along food chains, and the higher the food chain level, the greater the degree of biological contamination by radioactive substances (Buesseler, 2012; Alava and Gobas, 2016; Okamura et al., 2016).

Releasing radioactive wastewater to the ocean is not the only solution adoptable, however. With a 12.3-year half-life, $97 \%$ of the tritium contained in tanks will decay in 60 years, along with those isotopes of shorter half-life (Buesseler, 2020). Though TEPCO claims a lack of room for accumulating wastewater, there is still space for additional wastewater on land adjacent to FNDPP campus. The storage would allow radionuclides to decay in tanks, while buying time for development of new treatment techniques. There are also other ways to deal with the radioactive wastewater, such as underground burial, controlled vapor release, injection to geosphere, et al. but Japan has chosen the most cost-efficient, but most harmful one (Lu et al., 2021).

Concerns over contaminated fish devastated the regional fishing industry, and uncontrolled radionuclides released into the ocean would cause long-lasting effect to residents and people in other countries. Without fully discussion and negotiation with residents and neighboring countries, the unilateral decision by Japan has raised severe conflicts. Game theory has been wisely applied in such transboundary controversies in environmental protection (Jørgensen and Zaccour, 2001; Petrosjan and Zaccour, 2003; Ni and Wang, 2007; Jørgensen, 2010). Cardinal preferences of decision-makers (DMs) are the key factors of the correctness and accuracy of a model in classic game theory. However, in the issue of the Fukushima nuclear wastewater discharge conflict, much information including preferences of DMs is not sufficient, leading to limitations in the application of traditional game model. Graph Model for Conflict Resolution (GMCR) is a method between qualitative and quantitative analysis. It only needs limited information such as qualitative preferences of 
DMs to grasp a general and clear knowledge about the essential of the conflict, thereby helping forecast results of the conflict or trace the causes of the result.

This study has two main contributions. (1) In the existing research on nuclear wastewater discharge management, there is little analysis on the strategies of each DM. This study tries to list the options of each DM and combine them to form the possible results of the conflict event. (2) This study attempts to apply the GMCR model to the conflict of nuclear wastewater discharge, the local equilibrium and global equilibrium of are calculated, which provides a reference for the resolution of conflict events.

The contents of the remainder of the paper are as follows: Section 2 is dedicated to an introduction of the development of GMCR, while Section 3 presents the basic structure and definitions of the graph model. In Section 4, a graph model is structured according to the conflict of nuclear wastewater discharging into the ocean from FNDPP and the equilibriums with regard to different solution concepts are analyzed. Finally, Section 5 presents the concluding remarks.

\section{The development of GMCR}

Developed from normative game theory, GMCR is used to reveal how interactions among individual DMs or groups lead to a final conflict outcome (Kilgour et al., 1987; Fang et al., 1993). The use of a directed graph, which presents DMs' interactions consisting moves and counter-moves and preferences of each DM with respect to possible scenarios, differentiates GMCR from other conflict models. The current development in GMCR is focused on five aspects: preference information, stability concepts, inverse analysis, coalition GMCR and application.

As a characterization of values of DMs, preference information is the key ingredient in a conflict model and the early GMCR only takes into account simple preferences (Fang et al., 2003a, b). The strength of preference was conceived and developed later to deal with conflicts where a DM prefers one scenario greatly over another (Hamouda et al., 2004, 2006). In some circumstances, uncertainty can be present within preferences of one DM or more. Techniques for handling uncertain preferences were devised and improved, including unknown preference, fuzzy preference, grey preference and probabilistic preference (Li et al., 2004; Al-Mutairi et al., 2008a, b; Kuang et al., 2015; Silva et al., 2017; Zhao and Xu, 2017; Yu et al., 2019).

DMs may behave differently in a dispute because insights and attitudes to risks vary from person to person. Consequently, four fundamental solution concepts are provided, i.e. Nash stability (Nash), General Metarationality (GMR), Symmetric Metarationality (SMR) and Sequential Stability (SEQ), along with extended solution concepts such as Symmetric Sequential Stability (SSEQ), Mixed Symmetric Metarationality (MSMR), Limited-move Stability $\left(L_{h}\right)$ (Nash, 1950; Howard, 1971; Fraser and Hipel, 1984; Zagare, 1984; Rêgo and Vieira, 2017; Zhao et al., 2019).

Inverse analysis is a process to determine the preferences of DMs required to reach a particular state as a specified outcome or desired equilibrium in a conflict. Matrix inequalities are designed to present feasible regions of preferences under different solution definitions, and enumeration and optimization algorithm are applied in calculation in inverse GMCR (Kinsara et al., 2014; Wang et al., 2018; Tao et al., 2021).

Sometimes some DMs may form a coalition for the purpose of a better outcome, and this coalition formation inspired GMCR researchers to construct GMCR models with coalition (Kilgour et al., 2001). The application of GMCR is carried out along with the development of the model. GMCR has been widely used to analyze and settle controversies in the field of military, environmental governance, resource allocation (Fraser et al., 1990; Xiao et al., 2016; He et al., 2017).

Conflict of nuclear wastewater discharging 
MAEM

5,1

48

\section{The method of the GMCR}

The graph model is a model method used to solve the conflicts among different DMs. Different DMs take different options or strategies and form a series of feasible states by arrangement and combination. Each DM has its own cognition of the preference relationship of feasible states. Each feasible state can be served as a node in the graph, and one state can be transferred between other states. The directed arcs linked the different states are the options of the DMs, and DMs can control their own actions to achieve state that they wish to move to. The actions of the DMs have a direction, and some actions, once taken, cannot be withdrawn.

In the graph model, each state is a combination of options chosen by different DMs to achieve their goals. In fact, the strategies of each DM have their own selected options expressed as $\mathrm{O}_{1}, \mathrm{O}_{2} \ldots \mathrm{O}_{\mathrm{P}}$. The DM determines whether to select the option, if DM selects the option which is represented by "Y", if DM do not select the option which is represented by " $N$ ". The modeling process is shown in Figure 1. Assuming that all DMs have $p$ options, there will be $2^{\mathrm{P}}$ states in mathematical logic. However, in practical application, due to some contradictions between options, the number of feasible states is generally less than $2^{\mathrm{P}}$.

Based on the description of the graph model method, the definition of mathematical language can be given. It is assumed that there are multiple DMs $N=\{1,2, \ldots, n\}$ to determine their own options to form a state set $S=\left\{s_{1}, s_{2}, \ldots, s_{m}\right\}$, the transition among states can be controlled by the options $A_{k} \in S \times S$ taken by any DM $k \in N$. The motive for the state transition is the DMs' preference $P_{k}$, for which the mathematical expression of the conflict analysis graph model is as follows:

$$
\left\langle N, S,\left\{\left(D_{k}, P_{k}\right): k \in N\right\}\right\rangle
$$

After making clear the DMs, options, states and preferences, four kinds of equilibrium of GMCR definitions of Nash, General Metarationality (GMR), Symmetric Metarationality (SMR) and Sequential Stability (SEQ) are shown as follows.

Definition 1. Nash: For any $k \in N$, a state $s \in S$, and the Nash stable for DM $k$, as denoted by $s \in S_{k}^{R}$, if and only if $R_{k}^{+}(s)=\varnothing$.

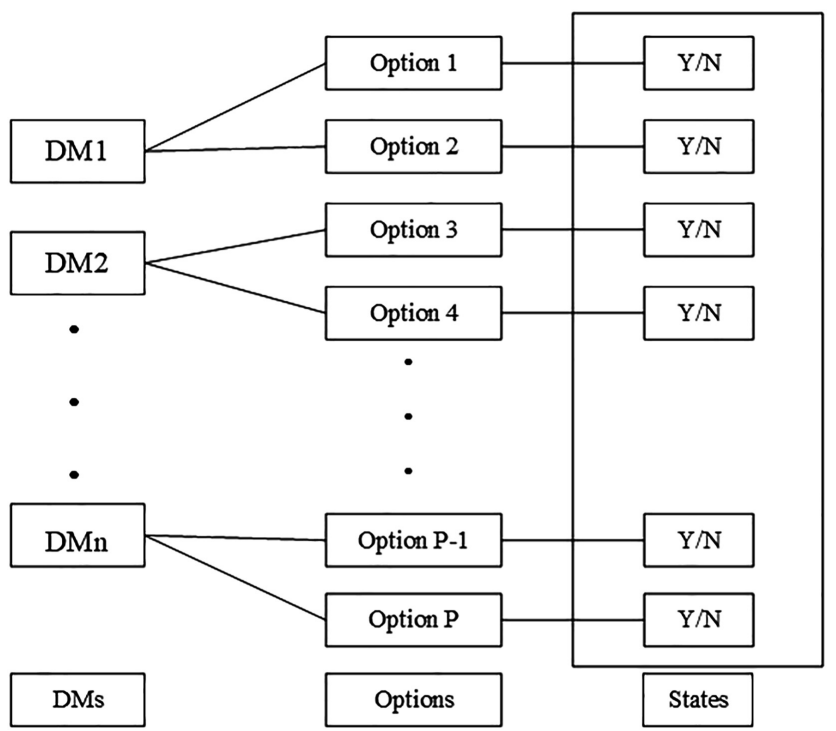

Figure 1.

The modeling process of the GMCR 
Definition 2. For any $k \in N$, a state $s \in S$, and the GMR stable for DM $k$, as denoted by $s \in S_{k}^{G M R}$, if and only if for every $s_{1} \in S_{k}^{+}(s)$, there exists at least one $s_{2} \in S_{q}\left(s_{1}\right)$ satisfying $s_{2} \precsim s$.

Definition 3. For any $k \in N$, a state $s \in S$, and the SMR stable for DM $k$, as denoted by $s \in S_{k}^{S M R}$, if and only if for every $s_{1} \in S_{k}^{+}(s)$, there exists at least one $s_{2} \in S_{q}\left(s_{1}\right)$ satisfying $s_{2} \lesssim s$, and $s_{3} \in S_{k}\left(s_{2}\right)$ satisfying $s_{3} \precsim s$.

Definition 4. For any $k \in N$, a state $s \in S$, and the GMR stable for DM $k$, as denoted by $s \in S_{k}^{S E Q}$, if and only if for every $s_{1} \in S_{k}^{+}(s)$, there exists at least one $s_{2} \in S_{q}^{+}\left(s_{1}\right)$ satisfying $s_{2} \precsim s$.

According to the definition of the four stabilities (Nash, GMR, SMR and SEQ), the interrelationships of solution concepts are shown in Figure 2.

\section{The conflict of discharging of nuclear wastewater}

This section describes the conflict of nuclear wastewater discharge into the ocean, constructs the DMs and their options and analyzes the equilibrium solution based on the relative preference of DMs.

\subsection{The background of the discharging of nuclear wastewater}

After 10 years of the Fukushima Nuclear Accident, Japanese government and TEPCO decided to discharge the nuclear wastewater into the Pacific Ocean over a course of 30 years on 13 April 2021. The water (cooling water, groundwater and rainwater) that cools the reactor core is processed by the Advanced Liquid Processing System (ALPS) and stored in tanks in the Fukushima Daiichi Nuclear Power Plant (FDNPP), however, all tanks will be filled with nuclear wastewater around 2022.

Despite repeated assurances from the Japanese government that radiation levels in the treated and diluted nuclear wastewater are lower than those in normal drinking water, the fact that ALPS is weak in handling ${ }^{14} \mathrm{C}$ and tritium makes those assurances unreliable. Once the nuclear wastewater containing radioactive elements is discharged into the ocean, it will pose a great threat to the surrounding marine environment, ecological safety and human health.

Local people, especially those involved in the fishing industry, strongly opposed the implementation of the decision, because the discharge of nuclear wastewater into the ocean would greatly damage the development of Japan's fishing industry. Meanwhile, Neighboring

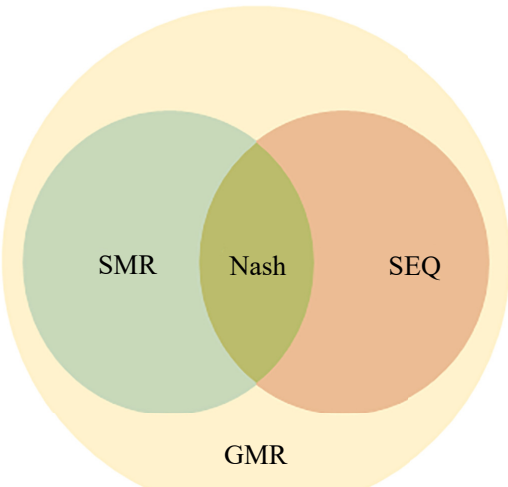

Figure 2.

The interrelationships of four stabilities (Nash, GMR, SMR, and SEQ) 
MAEM

5,1

50

countries including China, South Korea, Russia, and North Korea expressed strong opposition by issuing governmental statements. They argued that Japan had more ways to deal with nuclear wastewater, and that it was irresponsible to unilaterally adopt the cheapest way, which would harm the marine ecological security of surrounding countries.

\subsection{Decision-makers and options}

As described in 4.1, the DMs on the conflict over the discharge of nuclear water can be identified as the Japanese government and TEPCO (JGT), Japanese residents (JR) and neighboring countries (NC). DMs all have their own options, which eventually form feasible states as shown in Table 1.

According to Table 1, the three options of JGT are discharging nuclear wastewater into the ocean, discharging nuclear wastewater by other methods and storing nuclear wastewater. JR's option is resisting of discharging nuclear wastewater into the ocean and NC's option is imposing sanctions on the marine industry to JGT. And the integrated graph for the conflict of discharging of nuclear wastewater is shown in Figure 3.

$D M 1 J G T$

Discharging nuclear wastewater into the ocean

Discharging nuclear wastewater by other methods

Storing nuclear wastewater

$D M 2 J R$

Resisting of discharging nuclear wastewater into the ocean

$D M 3 N C$

Imposing sanctions on the marine industry on JGT

States

\section{DM1 JGT}

Discharging nuclear wastewater into the ocean

Discharging nuclear wastewater by other methods

Storing nuclear wastewater

Table 1.

The feasible states in the conflict of discharging of nuclear wastewater

\section{$D M 2 J R$}

$\begin{array}{lllllllllllllllllll}\text { Resisting of discharging nuclear wastewater into the ocean } & \text { Y } & \text { N } & \text { N } & \text { Y } & \text { Y }\end{array}$

DM3 NC

Imposing sanctions on the marine industry on JGT States
Figure 3.

The integrated graph for the conflict of discharging of nuclear wastewater

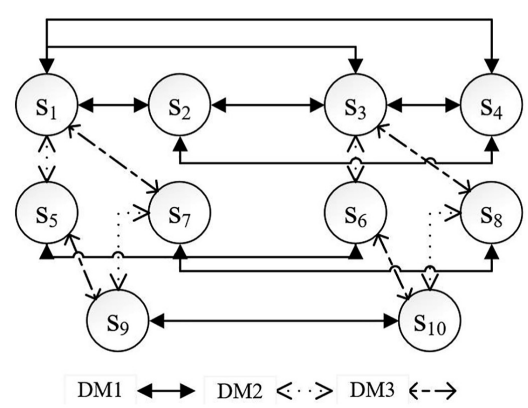

\begin{tabular}{lllll}
$\mathrm{Y}$ & $\mathrm{N}$ & $\mathrm{Y}$ & $\mathrm{N}$ & $\mathrm{Y}$ \\
$\mathrm{N}$ & $\mathrm{Y}$ & $\mathrm{Y}$ & $\mathrm{N}$ & $\mathrm{N}$ \\
$\mathrm{N}$ & $\mathrm{N}$ & $\mathrm{N}$ & $\mathrm{Y}$ & $\mathrm{N}$ \\
& & & & \\
$\mathrm{N}$ & $\mathrm{N}$ & $\mathrm{N}$ & $\mathrm{N}$ & $\mathrm{Y}$ \\
& & & & \\
$\mathrm{N}$ & $\mathrm{N}$ & $\mathrm{N}$ & $\mathrm{N}$ & $\mathrm{N}$ \\
$\mathrm{S}_{1}$ & $\mathrm{~S}_{2}$ & $\mathrm{~S}_{3}$ & $\mathrm{~S}_{4}$ & $\mathrm{~S}_{5}$ \\
& & & & \\
$\mathrm{Y}$ & $\mathrm{Y}$ & $\mathrm{Y}$ & $\mathrm{Y}$ & $\mathrm{Y}$ \\
$\mathrm{Y}$ & $\mathrm{N}$ & $\mathrm{Y}$ & $\mathrm{N}$ & $\mathrm{Y}$ \\
$\mathrm{N}$ & $\mathrm{N}$ & $\mathrm{N}$ & $\mathrm{N}$ & $\mathrm{N}$ \\
& & & & \\
$\mathrm{Y}$ & $\mathrm{N}$ & $\mathrm{N}$ & $\mathrm{Y}$ & $\mathrm{Y}$ \\
& & & & \\
$\mathrm{N}$ & $\mathrm{Y}$ & $\mathrm{Y}$ & $\mathrm{Y}$ & $\mathrm{Y}$ \\
$\mathrm{S}_{6}$ & $\mathrm{~S}_{7}$ & $\mathrm{~S}_{8}$ & $\mathrm{~S}_{9}$ & $\mathrm{~S}_{10}$ \\
\hline
\end{tabular}


Theoretically, there are five choices for the three DMs, which can form $2^{5}=32$ states in total, which are mathematically possible. However, there may be contradictions in DMs' options and some of the 32 states are infeasible. In FDNPP nuclear waste water discharging conflict, JGT has to choose at least one of its three options. If JGT does not select the option that discharging nuclear wastewater into the ocean, JR cannot select the option that resisting JGT, and NC cannot select the option that imposing sanctions on the marine industry to JGT. Besides, JGT's option of "discharging nuclear wastewater into the ocean" conflicts with the one of "storing nuclear water". It's also infeasible if JGT choose both to discharge nuclear wastewater into the ocean and other methods considering the processing cost. According to Ministry of Economics, Tread and Industry (METI) of Japan, compared to other options such as "injection and disposal into the geological formation", "release to the Atmosphere in the form of steam" and "underground burial and disposal after solidification or gelification", "release to the sea" is the method with lowest cost.

\subsection{Decision-makers' preferences}

In the GMCR, the DMs' preferences are the motive for the state transition, and DMs realize their own interests by changing their own options. According to the research group of MEIT's report on April 19, 2016, MEIT had considered various methods such as sealing the sewage with concrete after purification treatment, burying it underground or allowing it to evaporate into the atmosphere, but the cost of tens of billions to hundreds of billions of yen deterred the government. It only costs 1.7 billion to 3.4 billion yen to discharge the diluted tritium residual water into the ocean, which is very attractive in cost. The report also said that discharging nuclear sewage into the sea means that it can be completely treated in only 4 8 years, which is quite "cost-effective" in terms of time. So JGT hopes to discharge nuclear wastewater into the ocean, which will greatly save JGT expenditures. At the same time, JGT does not want to be boycotted by JR and sanctioned by NC. Neighboring countries such as China and South Korea have announced boycotts against the import of aquatic product from Japan, causing serious threats to Japanese Fisheries (Wu et al., 2020). If there is strong opposition and sanctions, JGT is more inclined to continue to store nuclear wastewater instead of adopting other methods to treat nuclear wastewater, because it will incur huge expenditures.

JR does not want JGT to discharge nuclear wastewater into the ocean, which will not be conducive to the development of local fisheries. JR does not want NC to impose fishery sanctions on JGT. JR hopes that it is the right choice for JCT to dispose of nuclear wastewater in a pollution-free manner. For NC, NC hopes to impose sanctions on JGT fisheries to force JGT not to discharge nuclear wastewater into the ocean. NC also hopes JR oppose JGT. The preference rankings of each DM are shown in Table 2.

\subsection{Equilibrium analysis}

According to the preference rankings of the three DMs, combined with the definition of Nash, GMR, SMR and SEQ equilibrium of the GMCR, the equilibrium solution of the conflict of the discharging of nuclear wastewater is shown in Table 3.

\begin{tabular}{ll}
\hline DM & Preference rankings \\
\hline JGT & $\mathrm{S}_{1}>\mathrm{S}_{4}>\mathrm{S}_{3}>\mathrm{S}_{7}>\mathrm{S}_{5}>\mathrm{S}_{8}>\mathrm{S}_{6}>\mathrm{S}_{9}>\mathrm{S}_{10}>\mathrm{S}_{2}$ \\
JR & $\mathrm{S}_{4}>\mathrm{S}_{2}>\mathrm{S}_{6}>\mathrm{S}_{5}>\mathrm{S}_{10}>\mathrm{S}_{9}>\mathrm{S}_{3}>\mathrm{S}_{1}>\mathrm{S}_{8}>\mathrm{S}_{7}$ \\
NC & $\mathrm{S}_{2}>\mathrm{S}_{4}>\mathrm{S}_{10}>\mathrm{S}_{8}>\mathrm{S}_{9}>\mathrm{S}_{7}>\mathrm{S}_{6}>\mathrm{S}_{3}>\mathrm{S}_{5}>\mathrm{S}_{1}$
\end{tabular}

Conflict of nuclear wastewater discharging 
MAEM

5,1

\section{2}

Table 3.

The equilibrium solution of the conflict of the discharging of nuclear wastewater
In Table 3 , the state represented by " $\sqrt{ }$ " indicates that a stability of DM individuals. If a state is the stability of all DMs, then the state is the equilibrium solution of the conflict. From Table 3, the equilibrium solution of the conflict problem of nuclear wastewater discharge is $\mathrm{S}_{9}$ and $\mathrm{S}_{4}, \mathrm{~S}_{9}$ satisfies the four equilibriums and $\mathrm{S}_{4}$ satisfies the three equilibriums of GMR, SMR and SEQ.

In the $\mathrm{S}_{9}$, JGT selects the option of discharging nuclear wastewater into the ocean, JR expresses opposition and NC imposes sanctions on JCT. The situation reflected in $\mathrm{S}_{9}$ is consistent with the current conflict situation. In this state, although the discharge of nuclear wastewater into the ocean can alleviate the financial pressure of JGT in a relatively short period of time, the pollution caused by the marine environment is irreversible. It will also seriously affect JR's life health and economic income. Similarly, the discharge of nuclear wastewater will also affect the marine environment of neighboring countries and even the world. In order to maintain the safety of its people, NC has to impose sanctions on JGT's seafood, which will also worsen diplomatic relations and cause greater economic losses.

In the $\mathrm{S}_{4}$, JGT selects the option of storing nuclear wastewater, while both JR and NC express their support. In this state, although JGT will increase storage costs to a certain extent, it protects the marine environment, guarantees JR's health and economic income and enhances JGT's diplomatic reputation, which is more conducive to international cooperation with NC. Economic foundation and international relations provide technical guarantee for more environmentally friendly treatment of nuclear wastewater in the future.

\section{Conclusion}

The conflict of nuclear wastewater discharge in Japan is a complex process, and there are a lot of uncertainties and unknowns in this process. It is difficult to quantify the effect function of each DM by game theory method, while the GMCR method can solve the conflict problem by analyzing the relative preference of DMs. In this study, GMCR method is used to solve the nuclear waste water discharge problem.

The results show that $S_{4}$ and $S_{9}$ are the equilibrium solutions to solve the conflict problem, and $S_{9}$ is in consist with the current situation. From a long-term perspective, this equilibrium is unfavorable for all DMs including JGT itself.

It is worth noting that $\mathrm{S}_{4}$ is another equilibrium in this graph model, which indicates that JGT to store the waste water is a potential outcome of the dispute in real world. In fact, Fukushima Prefecture still has enough space to store nuclear waste water, and other optional processing methods are available. Compared to $\mathrm{S}_{9}, \mathrm{~S}_{4}$ is an equilibrium for JGT with regard to the solution concepts mentioned above except for Nash Equilibrium, which means that JGT has the intention to leave $\mathrm{S}_{4}$ without considering other DMs' sanctions. Vice versa, if JR and

\begin{tabular}{|c|c|c|c|c|c|c|c|c|c|c|c|c|}
\hline States & $\begin{array}{l}\text { JGT } \\
\text { Nash }\end{array}$ & GMR & SMR & SEQ & $\begin{array}{l}\text { JR } \\
\text { Nash }\end{array}$ & GMR & SMR & SEQ & $\begin{array}{l}\mathrm{NC} \\
\text { Nash }\end{array}$ & GMR & SMR & SEQ \\
\hline $\begin{array}{l}\mathrm{S}_{1} \\
\mathrm{~S}_{2} \\
\mathrm{~S}_{3}\end{array}$ & $\sqrt{ }$ & $\sqrt{ }$ & $\sqrt{ }$ & $\sqrt{ }$ & $\sqrt{ }$ & $\sqrt{ }$ & $\sqrt{ }$ & $\sqrt{ }$ & $\sqrt{ }$ & $\sqrt{ }$ & $\sqrt{ }$ & $\sqrt{ }$ \\
\hline $\begin{array}{l}\mathrm{S}_{4} \\
\mathrm{~S}_{5} \\
\mathrm{~S}_{6}\end{array}$ & $\sqrt{ }$ & $\begin{array}{l}\sqrt{ } \\
\sqrt[V]{ } \\
\sqrt{ }\end{array}$ & $\begin{array}{l}\sqrt{ } \\
\sqrt[V]{ } \\
\sqrt{ }\end{array}$ & $\begin{array}{l}\sqrt{ } \\
\sqrt[V]{ }\end{array}$ & $\begin{array}{l}\sqrt{ } \\
\sqrt[V]{ }\end{array}$ & $\begin{array}{l}\sqrt{ } \\
\sqrt[V]{V}\end{array}$ & $\begin{array}{l}\sqrt{ } \\
\sqrt[V]{ }\end{array}$ & $\begin{array}{l}\sqrt{ } \\
\sqrt[V]{ }\end{array}$ & $\sqrt{ }$ & $\sqrt{ }$ & $\sqrt{ }$ & $\sqrt{ }$ \\
\hline $\begin{array}{l}\mathrm{S}_{7} \\
\mathrm{~S}_{8}\end{array}$ & $\sqrt{ }$ & $\sqrt[V]{V}$ & $\sqrt[V]{V}$ & $\sqrt{V}$ & & & & & $\sqrt{V}$ & $\sqrt{V}$ & $\sqrt{V}$ & $\sqrt{V}$ \\
\hline $\begin{array}{l}\mathrm{S}_{9} \\
\mathrm{~S}_{10}\end{array}$ & $\sqrt{ }$ & $\sqrt{ }$ & $\sqrt{ }$ & $\sqrt{ }$ & $\sqrt{V}$ & $\sqrt{V}$ & $\sqrt{V}$ & $\sqrt{V}$ & $\sqrt[V]{V}$ & $\sqrt[V]{V}$ & $\sqrt[V]{V}$ & $\sqrt[V]{ }$ \\
\hline
\end{tabular}


$\mathrm{NC}$ can take effective actions to penalize JGT's after it announces to release waste water into the ocean, JGT would probably hold back such decisions. $\mathrm{S}_{4}$ is more conducive to the protection of the marine environment. In the short term, it may increase the cost of JGT, but in the long term, this state has won both JR's support and maintenance relationship with NC.

In fact, the Japanese government holds the initiative on how to resolve the conflict of nuclear wastewater discharge. If the Japanese government only considers its immediate interests and unilaterally implements its decision to discharge nuclear wastewater into the ocean, it will inevitably cause serious losses. Before making a final decision, there is still some work that needs to be determined to be more conducive to solving the current conflict.

(1) Introduce a third-party assessment agency to re-examine the radioactivity of nuclear waste water to be discharged into the ocean.

(2) In response to the assessment report, the Japanese government should consult with other countries to jointly explore the disposal of nuclear wastewater.

(3) If nuclear waste is determined to be discharged into the ocean, the Japanese government should establish a complete compensation system, which should be endorsed by other stakeholders.

In future work, the more complex GMCR method attempts to solve the conflict problem of nuclear wastewater discharge into the sea. In the long run, the influence of changes in DMs' preferences on the equilibrium solution can be analyzed at different time points.

\section{References}

Al-Mutairi, M.S., Hipel, K.W. and Kamel, M.S. (2008a), "Fuzzy preferences in conflicts", Journal of Systems Science and Systems Engineering, Vol. 17 No. 3, pp. 257-276.

Al-Mutairi, M.S., Hipel, K.W. and Kamel, M.S. (2008b), "Trust and cooperation from a fuzzy perspective", Mathematics and Computers in Simulation, Vol. 76 Nos 5-6, pp. 430-446.

Alava, J.J. and Gobas, F.A.P.C. (2016), "Modeling 137Cs bioaccumulation in the salmon resident killer whale food web of the Northeastern Pacific following the Fukushima Nuclear Accident”, Science of the Total Environment, Vol. 544, pp. 56-67.

Buesseler, K.O. (2012), "Fishing for answers off Fukushima”, Science, Vol. 338 No. 6106, pp. 480-482.

Buesseler, K.O. (2020), "Opening the floodgates at Fukushima”, Science, Vol. 369 No. 6504, pp. 621-622.

Fang, L., Hipel, K.W. and Kilgour, D.M. (1993), Interactive Decision Making: The Graph Model for Conflict Resolution, John Wiley \& Sons, New York.

Fang, L., Hipel, K.W., Kilgour, D.M. and Peng, X. (2003a), “A decision support system for interactive decision making-part I: model formulation", IEEE Transactions on Systems, Man, and Cybernetics, Part C (Applications and Reviews), Vol. 33 No. 1, pp. 42-55.

Fang, L., Hipel, K.W., Kilgour, D.M. and Peng, X. (2003b), “A decision support system for interactive decision making-part II: analysis and output interpretation”, IEEE Transactions On Systems, Man, and Cybernetics, Part C (Applications and Reviews), Vol. 33 No. 1, pp. 56-66.

Fraser, N. and Hipel, K.W. (1984), Conflict Analysis: Models and Resolutions, North Holland, New York.

Fraser, N.M., Hipel, K.W., Jaworsky, J. and Zuljan, R. (1990), "A conflict analysis of the ArmenianAzerbaijani dispute", Journal of Conflict Resolution, Vol. 34 No. 4, pp. 652-677.

Hamouda, L., Kilgour, D.M. and Hipel, K.W. (2004), "Strength of preference in the graph model for conflict resolution”, Group Decision and Negotiation, Vol. 13 No. 5, pp. 449-462.

Hamouda, L., Kilgour, D.M. and Hipel, K.W. (2006), "Strength of preference in graph models for multiple-decision-maker conflicts", Applied Mathematics and Computation, Vol. 179 No. 1, pp. 314-327.

Conflict of nuclear

wastewater discharging 
MAEM

5,1

\section{4}

He, S., Kilgour, D.M. and Hipel, K.W. (2017), “A general hierarchical graph model for conflict resolution with application to greenhouse gas emission disputes between USA and China", European Journal of Operational Research, Vol. 257 No. 3, pp. 919-932.

Howard, N. (1971), Paradoxes of Rationality: Theory of Metagames and Political Behavior, M.I.T. Press, Cambridge, Mass, p. 248, 1971.

Jørgensen, S. (2010), "A dynamic game of waste management", Journal of Economic Dynamics and Control, Vol. 34 No. 2, pp. 258-265.

Jørgensen, S. and Zaccour, G. (2001), "Incentive equilibrium strategies and welfare allocation in a dynamic game of pollution control”, Automatica, Vol. 37 No. 1, pp. 29-36.

Kilgour, D.M., Hipel, K.W. and Fang, L. (1987), “The graph model for conflicts”, Automatica, Vol. 23 No. 1, pp. 41-55.

Kilgour, D.M., Hipel, K.W., Fang, L. and Peng, X.J. (2001), "Coalition analysis in group decision support”, Group Decision and Negotiation, Vol. 10 No. 2, pp. 159-175.

Kinsara, R.A., Kilgour, D.M. and Hipel, K.W. (2014), "Inverse approach to the graph model for conflict resolution”, IEEE Transactions on Systems, Man, and Cybernetics: Systems, Vol. 45 No. 5, pp. 734-742.

Kuang, H., Bashar, M.A., Hipel, K.W. and Kilgour, D.M. (2015), "Grey-based preference in a graph model for conflict resolution with multiple decision makers", IEEE Transactions on Systems, Man, and Cybernetics: Systems, Vol. 45 No. 9, pp. 1254-1267.

Li, K.W., Hipel, K.W., Kilgour, D.M. and Fang, L. (2004), "Preference uncertainty in the graph model for conflict resolution", IEEE Transactions on Systems, Man, and Cybernetics-Part A: Systems and Humans, Vol. 34 No. 4, pp. 507-520.

Lu, Y., Yuan, J., Du, D., Sun, B. and Yi, X. (2021), "Monitoring long-term ecological impacts from release of Fukushima radiation water into ocean", Geography and Sustainability, Vol. 2 No. 2, pp. 95-98.

Nash, J.F. (1950), "Equilibrium points in n-person games", Proceedings of the National Academy of Sciences, Vol. 36 No. 1, pp. 48-49.

Ni, D. and Wang, Y. (2007), "Sharing a polluted river", Games and Economic Behavior, Vol. 60 No. 1, pp. 176-186.

Nogrady, B. (2021), "Scientists OK plan to release one million tonnes of waste water from Fukushima", Nature. doi: 10.1038/d41586-021-01225-2.

Okamura, H., Ikeda, S., Morita, T. and Eguchi, S. (2016), "Risk assessment of radioisotope contamination for aquatic living resources in and around Japan”, Proceedings of the National Academy of Sciences, Vol. 113 No. 14, pp. 3838-3843.

Petrosjan, L. and Zaccour, G. (2003), "Time-consistent Shapley value allocation of pollution cost reduction", Journal of Economic Dynamics and Control, Vol. 27 No. 3, pp. 381-398.

Rêgo, L.C. and Vieira, G.I.A. (2017), "Symmetric sequential stability in the graph model for conflict resolution with multiple decision makers", Group Decision and Negotiation, Vol. 26 No. 4, pp. 775-792.

Silva, M.M., Kilgour, D.M., Hipel, K.W. and Costa, A.P.C.S. (2017), "Probabilistic composition of preferences in the graph model with application to the new Recife project", Journal of Legal Affairs and Dispute Resolution in Engineering and Construction, Vol. 9 No. 3, pp. 14-25.

Smith, J.N., Brown, R.M., Williams, W.J., Robert, M., Nelson, R. and Moran, S.B. (2015), “Arrival of the Fukushima radioactivity plume in North American continental waters", Proceedings of the National Academy of Sciences, Vol. 112 No. 5, pp. 1310-1315.

Suseno, H. and Wahono, I.B. (2018), "Present status of 137Cs in seawaters of the Lombok strait and the Flores sea at the Indonesia through flow (ITF) following the Fukushima accident”, Marine Pollution Bulletin, Vol. 127, pp. 458-462.

Tao, L., Su, X. and Javed, S.A. (2021), "Inverse preference optimization in the graph model for conflict resolution based on the genetic algorithm", Group Decision and Negotiation, Vol. 30 No. 2, pp. 1085-1112. 
TEPCO (2021a), "Radiation concentration estimates for each tank area", available at: https://www. tepco.co.jp/en/decommission/progress/watertreatment/images/tankarea_en.pdf.

TEPCO (2021b), “Treated water portal site”, available at: https://www4.tepco.co.jp/en/decommission/ progress/watertreatment/index-e.html.

TEPCO (2021c), "Measurement and analysis results for contaminated water treatment", available at: https://www.tepco.co.jp/en/hd/decommission/progress/watermanagement/purification/analysis/ index-e.html.

Wang, J., Hipel, K.W., Fang, L. and Dang, Y. (2018), "Matrix representations of the inverse problem in the graph model for conflict resolution”, European Journal of Operational Research, Vol. 270 No. 1, pp. 282-293.

Wu, H., Dai, D. and Li, Y. (2020), "Postponement of decision on Fukushima radioactive sewage disposal plan”, Foreign Nuclear News, Vol. 41 No. 11, pp. 19-21.

Xiao, Y., Hipel, K.W. and Fang, L. (2016), "Incorporating water demand management into a cooperative water allocation framework", Water Resources Management, Vol. 30 No. 9, pp. 2997-3012.

Yu, J., Hipel, K.W., Kilgour, D.M., Fang, L. and Yin, K. (2019), "Graph model under unknown and fuzzy preferences", IEEE Transactions on Fuzzy Systems, Vol. 28 No. 2, pp. 308-320.

Zagare, F.C. (1984), "Limited-move equilibria in $2 \times 2$ games", Theory and Decision, Vol. 16 No. 1, pp. 1-19.

Zhao, S. and Xu, H. (2017), "Grey option prioritization for the graph model for conflict resolution", Journal of Grey System, Vol. 29 No. 3, pp. 14-25.

Zhao, S., Xu, H., Hipel, K.W. and Fang, L. (2019), "Mixed stabilities for analyzing opponents' heterogeneous behavior within the graph model for conflict resolution", European Journal of Operational Research, Vol. 277 No. 2, pp. 621-632.

\section{Corresponding author}

Haojun Xu can be contacted at: oucxuhaojun@163.com
Conflict of nuclear

wastewater discharging

For instructions on how to order reprints of this article, please visit our website:

www.emeraldgrouppublishing.com/licensing/reprints.htm

Or contact us for further details: permissions@emeraldinsight.com 